\title{
Appreciating measurement
}

\author{
Brent A. Williams* \\ Department of Epidemiology and Health Services Research, Geisinger Health System, Danville, PA, USA
}

\begin{abstract}
The continuous evolution of medicine and medical-related research owes much to the amazing advances in measurement that have occurred over the last century or so. This perspective serves to bring due attention to the incredible importance of measurement, citing multiple salient examples from the field of cardiovascular disease.
\end{abstract}

I often say that when you can measure what you are speaking about, and express it in numbers, you know something about it; but when you cannot measure it, when you cannot express it in numbers, your knowledge is of a meagre and unsatisfactory kind; it may be the beginning of knowledge, but you have scarcely, in your thoughts, advanced to the stage of science, whatever the matter may be.

\section{-Attributed to Lord Kelvin, $1883^{1}$}

The continuous evolution of medicine and medical-related research owes much to the amazing advances in measurement that have occurred over the last century or so. Though, upon introspection, few would question that measurement is an indispensable and ubiquitous component of contemporary medicine and research, it is the opinion of this commentator that the historical evolution of measurement with its overwhelming and far-reaching impact in today's health care and research environments is largely underappreciated by those very individuals who incorporate these advances almost daily in their professional lives. This perspective serves to bring due attention to the incredible importance of measurement, and asks readers to ponder where health care might be if the information provided by some of the most common measurements in medicine was not available to assist clinical decision making.

In the contemporary health care environment, the successive steps of measure, assess, act prevail in many typical clinical scenarios. For instance, a brachial blood pressure is measured, an assessment is made whether the measure is "high", and an action (or lack thereof) is taken according to assessment of the measurement, such as whether and how to treat. A review of the history of medicine reveals that not that long ago, information pertaining to any bodily element (eg organ, blood constituent) or phenomena (eg blood pressure) within a person's interior was simply not accessible, let alone objectively measurable, or required extreme tactics to measure such as surgery, oftentimes after the subject had already passed ${ }^{2}$. Indeed, the measuring devices prior to the $20^{\text {th }}$ century were crude and largely limited to the five senses. Understandably, this inability to measure made it enormously difficult to understand disease processes (assess), let alone devise appropriate treatments to alleviate the disease or its more outward symptomatic manifestations (act).

The enormous importance of measurement advances toward executing the measure-assess-act triad for the benefit of human health has many notable examples, perhaps none greater than the discovery of $\mathrm{x}$-rays by Wilhelm Roentgen in the late $19^{\text {th }}$ century ${ }^{3}$. Roentgen discovered that these invisible rays could pass through certain solid objects revealing internal structures. Indeed, the first $\mathrm{x}$-ray image Roentgen ever produced depicted the bones of his wife's hand which proved that $\mathrm{x}$-rays were passing through flesh but not bone. Given the nature of this initial experiment, the potential for medical applications of this discovery was immediately recognized, and the translation of this measurement discovery toward improving human health was brisk to say the least. Jorgensen recounts the tale of a man in Montreal, Canada, who was shot in the leg on Christmas Day, $1895^{3}$. The bullet remained lodged in the man's leg and could not be located through surgical exploration, really the only available method for such a task at the time. Meanwhile, around the same time in Germany, Roentgen was in the process of discovering $\mathrm{x}$-rays. His discovery was first published on December 28, 1895, verified independently by several laboratories around the world over the next several weeks, and the poor bulletbearing man had the bullet discovered via x-ray and subsequently removed on February 7, 1896. How's that for swift translation from bench to bedside!

Another salient example lies in the field of cardiac imaging. The heart was historically a difficult organ to study (and measure) considering its constant motion and the perceived risk involved with any innovative procedure going inside or near arguably the body's most important organ ${ }^{4}$. Indeed, the pioneers who dared to attempt measuring any cardiac structural or functional attribute typically possessed a risk-taking demeanor and a healthy ego ${ }^{4}$. Now today, with advances in measurement, blockages in coronary arteries can be visualized and their severity quantified; pressure changes across a blockage can be measured as a means of describing its functional effect; and blood flow to various regions of the heart can be measured, mapped, and portrayed as images on a computer screen ${ }^{5-8}$. Hence, in the context of the measure-assess-act paradigm, structural and/ or functional coronary disease is measured, an assessment is made

Correspondence to: Brent A. Williams, Department of Epidemiology and Health Services Research, Geisinger Health System, 100 North Academy Avenue, Danville, PA 17822, Phone: 570.214.6594; Fax: 570.214.5170; Email: bawilliams2@geisinger.edu

Key words: technology, measurement, imaging, cardiology

Received: July 20, 2017; Accepted: August 10, 2017; Published: August 14, 2017 
whether the measures are "bad enough", and actions are chosen to alleviate any measured aberration especially with regard to the decision to perform percutaneous coronary intervention (PCI). Today, PCI is performed regularly for the treatment of both acute and chronic coronary disease with an estimated 500,000 PCIs performed annually in the United States in recent years'. Notwithstanding concerns about PCI overuse, its proper application relies extensively on the aforementioned measurement advances to identify just those patients who should benefit most from the procedure.

With an eye toward the future, measurement in health care and research will certainly expand. The exponential growth in technology in recent years makes this declaration virtually a guarantee. Clearly there is no foreseeable end to the incorporation of common laboratory tests and imaging techniques in clinical medicine. And much of research involves measuring known phenomena in new, better, and/or more detailed ways, or discovering new things and developing a method to measure them (e.g. biomarkers). Indeed, in the research arena, new measurement techniques often serve as impetus for new lines of research, and some researchers base entire careers almost exclusively on new measurement techniques (think-omics). While there is enormous enthusiasm around these new measurement methods, it remains to be seen what impact they will ultimately have on improving human health. In contrast, many attributes that are of primary importance to patients but defy objective measurement receive much less attention. Though patient-reported outcomes such as symptoms are increasingly acknowledged as an important endpoint within the context of patientcentered care, these measures appear to have limited incorporation in practice which might be partially attributed to the difficulty in measuring them.

To improve human health, first one must measure as a means of describing health states. Assessment of measurements for aberration is impetus for corrective action. Action is taken to remediate aberrations and improve health. A re-measure serves as determination of effect of the corrective action. The primacy of measurement as the starting point for improving health states cannot be understated. If you cannot measure, you cannot understand, and thus it is difficult to act in the most effective manner. So, the next time you measure that low-density lipoprotein (LDL) cholesterol, realize the LDL is elevated, and prescribe that statin, acknowledge appreciation for the measurement (and the measurement pioneers) which enabled you to take meaningful action to improve your patient's health ${ }^{10}$.

\section{References}

1. Accessed from https://en.wikiquote.org/wiki/William_Thomson, December 17, 2016.

2. Burnham JC. Health Care in America: A History. Johns Hopkins University Press, 2015 .

3. Jorgensen TJ. Strange Glow. Princeton University Press, 2016.

4. Forrester J. The Heart Healers. St. Martin's Press, 2015.

5. Bruschke AV, Sheldon WC, Shirey EK, Proudfit WL (2009) A half century of selective coronary arteriography. J Am Coll Cardiol 54: 2139-2144. [Crossref]

6. Williams BA, Dorn JM, LaMonte MJ, Donahue RP, Trevisan M et al. Evaluating the Prognostic Value of Positron Emission Tomography Myocardial Perfusion Imaging Using Automated Software to Calculate Perfusion Defect Size. Clin Cardiol 2012; 35: E14-E21. [Crossref]

7. Gould KL, Lipscomb K (1974) Effects of coronary stenoses on coronary flow reserve and resistance. Am J Cardiol 34: 48-55. [Crossref]

8. Toth GG, Johnson NP, Jeremias A, Pellicano M, Vranckx P, et al. (2016) Standardization of Fractional Flow Reserve Measurements. J Am Coll Cardiol 68: 742-753. [Crossref]

9. Writing Group Members, Mozaffarian D, Benjamin EJ, Go AS, Arnett DK, et al. (2016) Heart Disease and Stroke Statistics-2016 Update: A Report From the American Heart Association. Circulation 133: e38-360. [Crossref]

10. Friedewald WT, Levy RI, Fredrickson DS. Estimation of the concentration of lowdensity lipoprotein cholesterol in plasma, without use of the preparative ultracentrifuge. Clin Chem 1972; 18: 499-502. [Crossref]

Copyright: (C2017 Williams BA. This is an open-access article distributed under the terms of the Creative Commons Attribution License, which permits unrestricted use, distribution, and reproduction in any medium, provided the original author and source are credited. 